\title{
Neonatal Tyrosinaemia:
}

\author{
A Follow-up Study
}

\author{
M. W. PARTINGTON`, D. J. DELAHAYE, R. E. MASOTTI, J. H. READ, and \\ B. ROBERTS
}

From the Departments of Paediatrics and Preventive Medicine, Queen's University, Kingston, Ontario, Canada

A raised blood tyrosine level (tyrosinaemia) is quite common during the neonatal period, especially in premature babies given high protein diets (Menkes and Avery, 1963; Mathews and Partington, 1964; Light, Berry, and Sutherland, 1966; Avery et al., 1967; Partington, 1968). Despite the gross disturbance in tyrosine metabolism, no unequivocal ill effects have been found at the time the blood tyrosine level is raised. The major concern now is whether this transient hyperaminoacidaemia has any long-term ill effects on the child, particularly with regard to intellectual development.

Menkes and his colleagues (Menkes and Avery, 1963; Menkes, Chernick, and Ringel, 1966) studied a group of premature babies similar to the one reported here. 65 premature infants were followed up in the second year of life, of whom 24 had had neonatal tyrosinaemia: no significant neurological or developmental differences were found between those infants who had had neonatal tyrosinaemia and those who had not. We are reporting a similar follow-up study.

\section{Material and Methods}

Methods of management, observation, and selection of babies in the newborn period have been described previously (Mathews and Partington, 1964; Partington and Mathews, 1966; Partington, 1968). Babies of low birthweight (less than $2500 \mathrm{~g}$.) were allotted to a low or high tyrosine group according to whether the highest plasma tyrosine recorded in the neonatal period was below or above $10 \mathrm{mg} . / 100 \mathrm{ml}$.

Two follow-up assessments were made, the first between the ages of 1 and 3 years, and the second in the 4th year of life. Table I compares the distributions of sex, gestational age, birthweight, and 'maturity' (Yerushalmy et al., 1965) of the children seen for each of these assessments with the population of babies from which they were drawn. It was concluded that in these

Received August 4, 1967.

* Queen Elizabeth II Scientist. respects the children seen at both follow-up clinics were representative of the original population.

First follow-up. Two children were seen on one day: they were first weighed (bar scales) and measured (head circumference; supine length with a fixed headboard and moveable footboard) by the same research nurse. The child was then seen in turn by two paediatricians for developmental assessment. The order in which the children were seen by each paediatrician was alternated throughout the series. The paediatrician

TABLE I

Comparison of Babies Seen for Follow-up Assessment with the Newborn Group

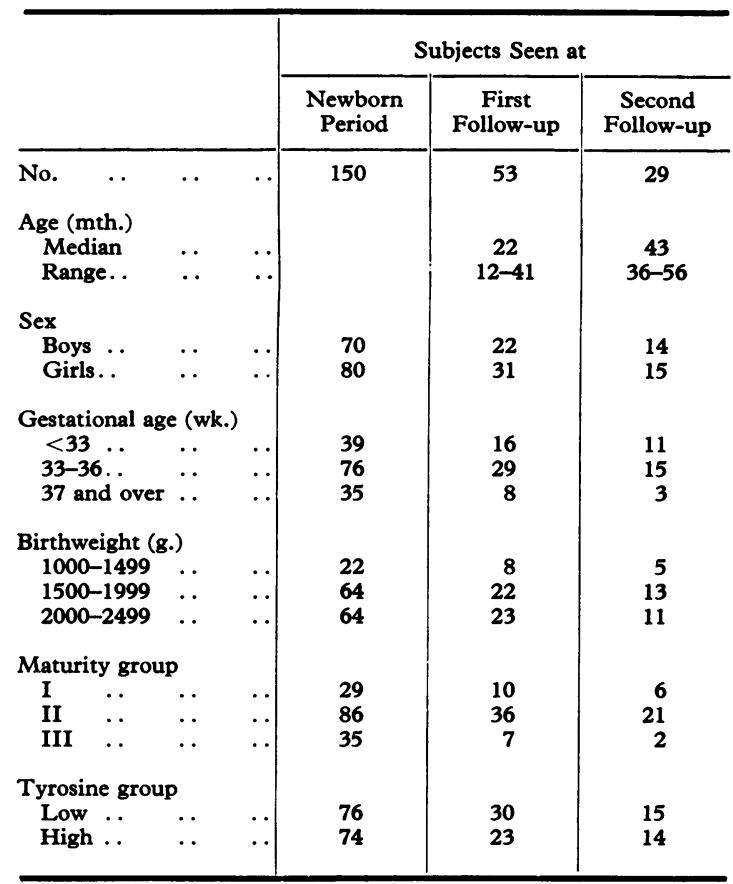


was given full details of the child's case history except for whether he had had a raised plasma tyrosine level in the neonatal period or not. The mother accompanied the child at the interview. A 'mental age' (MA) was assigned to the child on the basis of the history and simple developmental tests adapted from Gesell (Gesell and Amatruda, 1947). Neither doctor was aware of the other's assessment. The child was then seen by a third paediatrician who took a clinical history and carried out a full physical examination. The child's history of illness was scored according to the method of Valadian, Stuart, and Reed (1959). The whole process took about two hours for each child.

Second follow-up. The children were tested by a psychologist. The children were seen alone unless the mother's presence was necessary for co-operation. Each child was tested on the Stanford-Binet Intelligence Scale, Form L-M, 1960 Revision. Selected StanfordBinet subtests (form board, copying forms, digit span) and some additional tests (right-left reversals, coloured forms, drawing a line between horizontal lines one-half, one-quarter, and one-eighth of an inch apart) were used, and simple observations of clarity of speech and handedness were made.

\section{Results}

First follow-up. An attempt was made to recall 81 children but only 53 returned. The commonest reason for failure to return was that the family had moved from the district, but some parents were uncooperative. The follow-up routine proved cumbersome, and in some cases it was not possible to get the patient and all 4 professional people together at the same time. 3 children (all from the high tyrosine group) had died. 2 children, from separate families, were found dead in their cots at the age of 10 weeks, with no preceding history of illness. One of these sudden unexpected deaths was ascribed, after necropsy, to acute interstitial pneumonia; the other was ascribed, without necropsy, to bronchopneumonia. The third child died at 9 months of age after repeated hospital admissions for idiopathic renal acidosis.

Table II compares the sex, gestational age, birthweight, and age at time of follow-up of these children according to whether or not they had had neonatal tyrosinaemia. The median age at followup was the same for each group with a similar age distribution. There were slight differences in sex distribution and birthweight, but these were small.

History of illness. An 'illness score' was given to the child for each 6 months of the child's life using the scoring system of Valadian et al. (1959) modified for our own use. The total score for the child's life was then divided by his age in months to give an 'illness quotient'. The mean illness
TABLE II

Sex, Gestational Age, Birthweight, and Age at Testing of Low and High Tyrosine Groups at First Follow-up

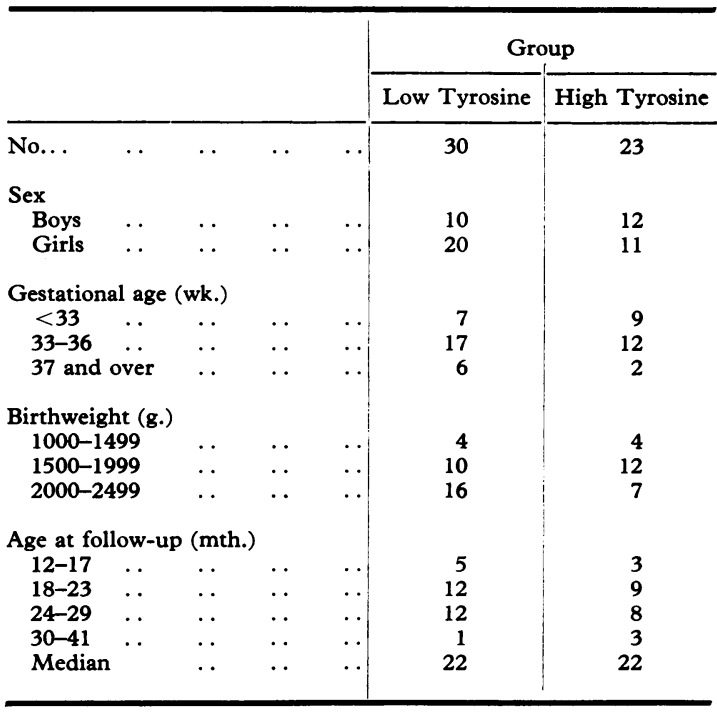

quotient for the low tyrosine group was $0 \cdot 188$ (SE 0.034 ) and 0.336 (SE 0.023 ) for the high tyrosine group. This difference was statistically significant $(t=1.972 ; n=51 ; p \simeq 0.05)$. On inspection of the scores for the 6-month age periods it was apparent that this difference was almost entirely due to the large amount of illness of 4 babies in the high tyrosine group. All 4 babies had had severe respiratory infections, one with a pulmonary abscess, another with associated convulsions. Only one child in the low tyrosine group had had a comparable illness. If these 4 sick babies are combined with the 3 deaths, the incidence of severe illness in the first year of life was 7 out of 26 in the high tyrosine group compared with 1 out of 30 in the low tyrosine group.

Two other boys from the high tyrosine group, both born in 1965 and not recalled for follow-up, were known to have died. One, at the age of 14 months, had a brief history of irritability followed by convulsions, collapse, and death within 16 hours of the onset of the illness; interstitial pneumonia, bronchopneumonia, and cerebral oedema were found at necropsy. The second child died at the age of 13 months from an aspiration pneumonia after a 4-day history of gastro-enteritis (confirmed at necropsy).

Physical examination. The physical measurements of the two groups are compared in Table III. 
The high tyrosine group had a significantly greater mean weight and head circumference; this group's mean height was also slightly greater but not at a statistically significant level.

These findings were unexpected and remain unexplained. In view of the association between head circumference and intelligence ( $O$ 'Connell, Feldt, and Stickler, 1965), the measurements were examined closely. There were 2 children with microcephaly (head circumferences $>3$ SD below the mean for their age and sex) in the low tyrosine group; removing these from the comparison still left a significant difference between the group means. The individual measurements were then converted to $\mathrm{Z}$ scores using the mean and standard deviation appropriate to the child's age and sex (Holt, McIntosh, and Barnett, 1962); a significant difference was still found $(t=1.99 ; n=49$; $\mathrm{p} \simeq 0.05$ ).

Neurological abnormalities were about the same in each group. In the low tyrosine group there was 1 child with a spastic quadriplegia and 1 with a mild spastic diplegia; in the high tyrosine group there was 1 child with a spastic diplegia and 2 others with shortened Achilles tendons, possibly attributable to spasticity. Strabismus, minor congenital abnormalities, haemangiomata, and umbilical hernia were found in 2 or 3 children in each group.

Developmental assessments. A comparison of the developmental quotients (DQ) between the low and high tyrosine groups is shown in Table IV. The DQs are presented for each paediatrician separately as raw scores, and as scores corrected for the degree of prematurity (i.e. by reducing the chronological age (CA) by the appropriate number of months in the equation $100 \times \mathrm{MA} / \mathrm{CA}=\mathrm{DQ}$ ). There were no significant differences between the
TABLE III

Physical Measurements of Low and High Tyrosine Groups at First Follow-up

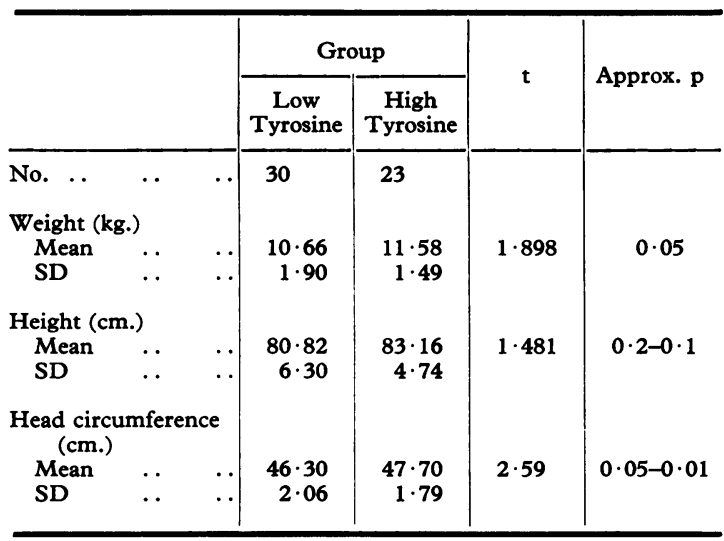

means for the two groups. There was a systematic and significant difference between the $D Q s$ assigned by each paediatrician, paediatrician $A$ giving consistently higher scores than paediatrician $\mathbf{B}$.

Second follow-up. Twenty-nine children seen at the first follow-up were recalled and successfully tested at the second follow-up, 14 from the high tyrosine group and 15 from the low tyrosine group (Table V). The median age at which they were tested was the same and the groups were comparable in gestational age and birthweight. There were more girls than boys in the low tyrosine group and more boys than girls the high tyrosine group, but these differences were not statistically significant $\left(\chi^{2}=1 \cdot 68 ; 0 \cdot 2>\mathrm{p}>0 \cdot 1\right)$.

Speech was observed to be clear in 8 children from the low tyrosine group and in 6 from the high

TABLE IV

Comparison Between Developmental Quotients Uncorrected and Corrected for Prematurity in Low and High Tyrosine Groups at First Follow-up

\begin{tabular}{|c|c|c|c|c|c|c|c|}
\hline & & \multicolumn{4}{|c|}{ Developmental Quotient } & \multirow{3}{*}{$\mathbf{t}$} & \multirow{3}{*}{ Approx. $p$} \\
\hline & & \multicolumn{2}{|c|}{ Low Tyrosine } & \multicolumn{2}{|c|}{ High Tyrosine } & & \\
\hline & & Mean & $\mathrm{SE}^{\star}$ & Mean & SE & & \\
\hline $\begin{array}{r}\text { Paediatrician A } \\
\text { Raw scores.. } \\
\text { Corrected .. }\end{array}$ & $\begin{array}{l}. . \\
. .\end{array}$ & $\begin{array}{r}96.9 \\
102.9\end{array}$ & $\begin{array}{l}1 \cdot 69 \\
2 \cdot 13\end{array}$ & $\begin{array}{r}94 \cdot 7 \\
102 \cdot 8\end{array}$ & $\begin{array}{l}1 \cdot 88 \\
2 \cdot 27\end{array}$ & $\begin{array}{l}0.863 \\
0.316\end{array}$ & $\begin{array}{l}0.380 \\
0.975\end{array}$ \\
\hline $\begin{array}{r}\text { Paediatrician B } \\
\text { Raw scores.. } \\
\text { Corrected .. }\end{array}$ & .. & $\begin{array}{l}89 \cdot 8 \\
95 \cdot 3\end{array}$ & $\begin{array}{l}2 \cdot 02 \\
2 \cdot 35\end{array}$ & $\begin{array}{l}88 \cdot 3 \\
95 \cdot 8\end{array}$ & $\begin{array}{l}2 \cdot 20 \\
2 \cdot 52\end{array}$ & $\begin{array}{l}0.503 \\
0 \cdot 148\end{array}$ & $\begin{array}{l}0.600 \\
0.880\end{array}$ \\
\hline
\end{tabular}

$\star \mathrm{SE}=$ standard error. 
TABLE V

Sex, Gestational Age, Birthweight, and Age at Testing of Low and High Tyrosine Groups at Second Follow-up

\begin{tabular}{|c|c|c|c|c|c|c|}
\hline & & & & & \multicolumn{2}{|c|}{ Group } \\
\hline & & & & & Low Tyrosine & High Tyrosine \\
\hline No... & $\cdots$ & $\cdots$ & . & $\cdots$ & 15 & 14 \\
\hline $\begin{array}{l}\text { Sex } \\
\text { Boys } \\
\text { Girls }\end{array}$ & $\begin{array}{l}\cdots \\
\cdots\end{array}$ & $\begin{array}{l}\cdots \\
\cdots\end{array}$ & $\cdots$ & $\cdots$ & $\begin{array}{r}5 \\
10\end{array}$ & $\begin{array}{l}9 \\
5\end{array}$ \\
\hline \multicolumn{7}{|c|}{ Gestational age (wk.) } \\
\hline $\begin{array}{l}<33 \\
33-36 \\
37 \text { and }\end{array}$ & $\begin{array}{l}\cdots \\
\cdots \\
\text { over }\end{array}$ & $\begin{array}{l}\cdots \\
\cdots \\
\cdots\end{array}$ & $\begin{array}{l}\cdots \\
\cdots \\
\cdots\end{array}$ & $\begin{array}{l}\cdots \\
\cdots \\
\cdots\end{array}$ & $\begin{array}{l}5 \\
8 \\
2\end{array}$ & $\begin{array}{l}6 \\
7 \\
1\end{array}$ \\
\hline $\begin{array}{r}\text { Birthweigh } \\
1000-14 \\
1500-19 \\
2000-24\end{array}$ & $\begin{array}{l}\text { t }(\mathrm{g} \\
99 \\
99 \\
99\end{array}$ & $\begin{array}{l}\cdots \\
\cdots \\
\cdots\end{array}$ & $\begin{array}{l}\cdots \\
\cdots \\
\cdots\end{array}$ & $\begin{array}{l}\ldots \\
\cdots \\
\cdots\end{array}$ & $\begin{array}{l}2 \\
6 \\
7\end{array}$ & $\begin{array}{l}3 \\
7 \\
4\end{array}$ \\
\hline $\begin{array}{c}\text { Age at test } \\
36-41 \\
42-47 \\
>48 \\
\text { Median }\end{array}$ & $\begin{array}{c}\text { ting } \\
\ldots \\
\ldots \\
\ldots \\
\ldots\end{array}$ & $\begin{array}{c}\text { th.) } \\
\cdots \\
\cdots \\
\cdots \\
\cdots\end{array}$ & $\begin{array}{l}\cdots \\
\cdots \\
\cdots\end{array}$ & $\begin{array}{l}\cdots \\
\cdots \\
\cdots \\
\cdots\end{array}$ & $\begin{array}{r}5 \\
8 \\
2 \\
43\end{array}$ & $\begin{array}{r}5 \\
5 \\
4 \\
43\end{array}$ \\
\hline
\end{tabular}

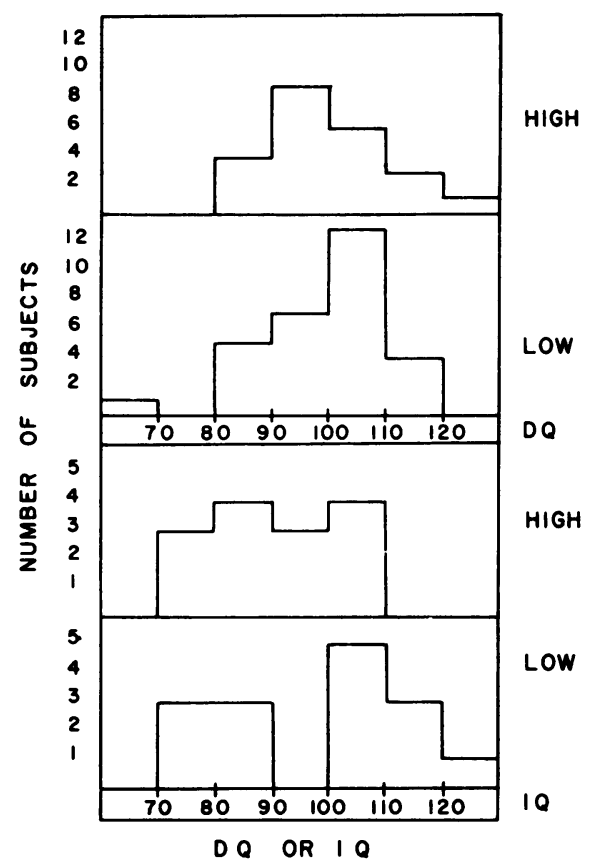

FIG.-Frequency distribution of $D Q s$ (at median age of 22 months) and IQs (at median age of 43 months) in the low and high tyrosine groups. tyrosine group. There were 2 left-handed children in each group. The mean intelligence quotient (IQ) of the low tyrosine group was $96 \cdot 5$ (SD 17.3) and of the high tyrosine group was $89 \cdot 4$ (SD 11.7). This difference was not significant $(t=1 \cdot 29$; d.f. $=27 ; 0.3>p>0 \cdot 2$ ).

The groups were compared $\left(\chi^{2}\right)$ in each of the Stanford-Binet subtests and the additional tests used. No significant differences were found.

In the Fig. the DQs (average of corrected scores of paediatricians A and B) and the IQs of the low and high tyrosine groups are shown as frequency distributions.

\section{Discussion}

Our findings have been essentially negative and agree with those of Menkes et al. (1966). It is still possible that neonatal tyrosinaemia causes subtle alterations in the behaviour or development of the child which we are unable to identify by our relatively crude methods of observation. The significantly larger mean head circumference or the increased incidence of severe illness, particularly respiratory infections, in the first 6 months of life of the high tyrosine group might be examples of this. Nevertheless, our present evidence seems enough to warrant the conclusion that neonatal tyrosinaemia has no gross effects on the subsequent development of the child.

This conclusion is surprising in view of the marked disturbance of amino acid metabolism that occurs in neonatal tyrosinaemia. The plasma tyrosine level may be 10-20 times higher than adult levels for 2 or 3 weeks, with peak values up to 30 times the normal. At the same time, there is a massive formation of the ketoacids of tyrosine, which are normally found only in very small quantities. At this time of life the brain is growing rapidly and, by analogy with phenylketonuria, maple syrup urine disease, histidinaemia, and homocystinuria, one might well expect harmful effects from neonatal tyrosinaemia, particularly on intellectual development. Furthermore, if the transient enzyme deficiency responsible for neonatal tyrosinaemia is, in fact, the same as the primary lesion suggested for hereditary tyrosinaemia (Halvorsen et al., 1966) one would expect vomiting, failure to thrive, haemorrhagic phenomena, liver failure, and renal tubular defects in those babies where tyrosinaemia persisted for more than a very short time. Such is not the case (Woolf, 1966; Partington and Mathews, 1966; Partington, 1968).

Two patients have been reported where prolonged neonatal tyrosinaemia or tyrosyluria was accompanied by symptoms. One child (Auerbach et al., 
1963) failed to thrive and had a voracious appetite; the clinical picture and biochemical abnormalities cleared spontaneously during hospitalization. The second child (Menkes and Jervis, 1961), at the age of 4 months, showed failure to thrive, spasticity, and generalized convulsions; tyrosyluria and the symptoms disappeared rapidly on treatment with a low phenylalanine diet. The relation between the biochemical abnormality and the clinical picture is not clear in either of these cases.

In practice, neonatal tyrosinaemia and tyrosyluria will continue to cause concern in case-finding programmes for metabolic disorders. Tyrosyluria may give a transient colour with $\mathrm{FeCl}_{3}$ and a positive 2-4 dinitrophenylhydrazine test (Partington, 1968). Neonatal tyrosinaemia may be associated with slight increases in the blood phenylalanine level sufficient to give positive Guthrie tests. Tyrosinaemia is easily demonstrated by amino acid paper chromatography (Scriver, Davies, and Cullen, 1964), but a raised blood tyrosine level may also be the first abnormal finding in hereditary tyrosinaemia (Larochelle et al., 1967).

We would personally advocate, though with no supporting evidence, the use of lower protein diets for the feeding of premature infants in order to reduce the incidence of neonatal tyrosinaemia, especially since there is no demonstrable advantage to daily protein intakes higher than $4.0 \mathrm{~g} . / \mathrm{kg}$. (Davidson et al., 1967). Intuitively, we feel that, if a gross abnormality of amino acid metabolism can be avoided, it should be. The alternative course of giving large doses of ascorbic acid (Light et al., 1966) seems illogical when no deficiency of ascorbic acid is demonstrable (Mathews and Partington, 1964) and when a more natural and physiological solution is at hand.

\section{Summary}

Twenty-three children who had had neonatal tyrosinaemia were assessed at a median age of 22 months; 14 of these were reassessed at a median age of 43 months. When compared with a control group, no neurological or developmental differences were found.
We wish to thank Mrs. Frances Strick and Mrs. Norma Roberts for their willing help, and Dr. Dugal Campbell for advice.

This work was supported by grants (Nos. 605-7-280 and 605-13-83) of the National Health Grants Programme and by the Ontario Association for the Mentally Retarded.

\section{REFERENCES}

Auerbach, V. H., DiGeorge, A. M., Brigham, M. P., and Dobbs, J. M. (1963). Delayed maturation of tyrosine metabolism in a full-term sibling of a child with phenylketonuria. $\mathcal{F}$. Pediat., $62,938$.

Avery, M. E., Clow, C. L., Menkes, J. H., Ramos, A., Scriver, C. R., Stern, L., and Wasserman, B. P. (1967). Transient tyrosinemia of the newborn: dietary and clinical aspects. Pediatrics, 39, 378.

Davidson, M., Levine, S. Z., Bauer, C. M., and Dann, M. (1967). Feeding studies in low-birth-weight infants. I. Relationships of dietary protein, fat, and electrolyte to rates of weight gain, clinical courses, and serum chemical concentrations. F. Pediat., 70, 695.

Gesell, A. L., and Amatruda, C. S. (1947). Developmental Diagnosis, 2nd ed. Hoeber, New York.

Halvorsen, S., Pande, H., Loken, A. C., and Gjessing, L. R. (1966). Tyrosinosis: a study of 6 cases. Arch. Dis Childh., 41, 238.

Holt, L. E., Jr., McIntosh, R., and Barnett, H. L. (1962). Pediatrics, 13th ed., p. 1332. Appleton-Century-Crofts, New York.

Larochelle, J., Mortezai, A., Belanger, M., Tremblay, M., Claveau, J. C., and Aubin, G. (1967). Experience with 37 infants with tyrosinemia. Canad. med. Ass. F., 97, 1051.

Light, I. J., Berry, H. K., and Sutherland, J. M. (1966). Aminoacidemia of prematurity. Its response to ascorbic acid. Amer. f. Dis. Child., 112, 229.

Mathews, J., and Partington, M. W. (1964). The plasma tyrosine levels of premature babies. Arch. Dis. Childh., 39, 371 .

Menkes, J. H., and Avery, M. E. (1963). The metabolism of phenylalanine and tyrosine in the premature infant. Bull. fohns Hopk. Hosp., 113, 301.

- Chernick, V., and Ringel, B. (1966). Effect of elevated blood tyrosine on subsequent intellectual development of premature infants. F. Pediat., 69, 583.

-, and Jervis, G. A. (1961). Developmental retardation associated with an abnormality in tyrosine metabolism. Pediatrics, 28, 399.

O'Connell, E. J., Feldt, R. H., and Stickler, G. B. (1965). Head circumference, mental retardation, and growth failure. ibid., 36, 62.

Partington, M. W. (1968). Neonatal tyrosinaemia. Biol. Neonat. (Basel). In the press.

-, and Mathews, J. (1966). The relation of plasma tyrosine level to weight gain of premature infants. F. Pediat., 68, 749.

Scriver, C. R., Davies, E., and Cullen, A. M. (1964). Application of a simple micromethod to the screening of plasma for a variety of aminoacidopathies. Lancet, 2, 230.

Valadian, I., Stuart, H. C., and Reed, R. B. (1959). Patterns of illness experience. Pediatrics, 24, 941.

Woolf, L. I. (1966). Symposium of Tyrosinosis. Universitetsforlaget, Oslo.

Yerushalmy, J., van den Berg, B. J., Erherdt, C. L., and Jacobziner, H. (1965). Birth weight and gestation as indices of 'immaturity'. Amer. F. Dis. Child., 109, 43. 